\title{
Performance Measurement of Small and Medium Enterprises (SMEs) in Pakistan
}

\author{
Mian Awais Shahbaz \\ UCP Business School, \\ University of the Central Punjab, Lahore .Pakistan \\ Asifah Javed \\ UCP Business School, \\ University of the Central Punjab, Lahore .Pakistan \\ Amina Dar \\ UCP Business School, \\ University of the Central Punjab , Lahore .Pakistan \\ Tanzeela Sattar \\ UCP Business School, \\ University of the Central Punjab , Lahore .Pakistan
}

\begin{abstract}
This paper examines the performance of small and medium enterprises in Pakistan through primary data collection from 199 business concerns. The study shows that most of the people maintain record of their revenues to measure performance of their organizations. There are many approaches used for performance evaluation but in Pakistan these approaches are not very much popular for performance measurement. Paper analysis those approaches more commonly used in Pakistan for measuring performance for small businesses.
\end{abstract}

Keywords: Performance evaluation, small and medium business, SMEs, Pakistan.

\section{INTRODUCTION}

Companies of all sizes need to implement a streamlined accounting system in order to accurately record and report business transactions, keep track of invoices and reduce problems with tax authorities and the International Reporting Standards (IRS). Accounting procedures are typically coordinated by a CPA or financial manager who is responsible for recording all incoming and outgoing transactions, maintaining consistent records and creating financial statements at the end of each financial period.

Performance management is the processes where by an organization's programs, investments and acquisitions reached to the desired results by using some parameters which are established by the organization By using following approaches small organizations can evaluate/measure their performance.

\section{1: Goal Approach}

Goal approach measures the degree to which an organization accomplishes its goals. This approach focuses on vision, mission, aims and objectives which an organization set before it. 


\section{2: System Approach}

Under this approach, an organization's performance is measured by appraising its capability to attain resources or input.

\section{3: Balance Scorecard Approach}

In this approach, an organization can evaluate its performance on the grounds of four aspects in which financial measures, internal process, quality and learning are incorporated.

\section{4: Hybrid Approach}

Hybrid approach is an approach in which a business organization's performance can be evaluated by using both either financial measures like net profit, earning per share and nonfinancial measures like employee turnover, customer satisfaction.

\section{5: comparative Analysis Approach}

In this approach organization compare its performance with another organization which is quite similar to it. It is just like the benchmarking.

\section{6: Ineffectiveness Approach}

Organization performance can be evaluated by focusing on those key factors which decelerate or preclude the growth of the organization.

\section{7: Stakeholder Approach}

This approach measures the extent of an organization's ability to meet the needs and expectations of its stakeholders.

\section{Objectives of Study}

The basic and the primary objective behind measures are to improve performance. For timely corrective actions, effective and efficient performance measurement is vital.

Following are the key objectives for measuring small organization performance.

- To evaluate, how much efficiently organization is performing.

- To ensure the managers that their subordinates are performing their jobs accurately and doing the right things.

- To budget: budgets are the basic tools for performance improvement.

- To motivate: Considerable goals are given to employees to be achieved and then focus on employee's work and philosophy by using performance measurement tools and at the end rewarded employees by periodic accomplishments.

- To celebrate: It is needed for the organization to celebrate their employee's accomplishments and give them a sense of individual and collective relevance.

- To ensure the stakeholders that organization is performing well, doing good job and in safe hands.

- To learn grounds behind good or bad performance.

\section{Significance of Study}

Performance Evaluation is the most important part of performance management. It focuses on performance improvement. Success $f$ an organization is impossible without knowing about; what to improve? Where to allocate or re-allocate resources? How to compete others? Whether organization is improving or declining? Whether or which policies, procedures, or employees are producing desired results that are cost effective and efficient? 
In this research, main focus is on small businesses of Lahore, because for developing countries like Pakistan, small businesses act as pillar of economy.

\section{LITERATURE REVIEWS}

A number of studies have been conducted on the issues regarding the performance measurement of the small business organizations'. Some of these are quoted here. Garengo et al (2005) stated that Performance Measurement System plays a vital role in managerial development of small organizations But Short Term Strategic Panning \& Lack of Financial and Human Resources are two main barriers due to which organizations don't follow this system.

Kaplan, Norton (1992) explained that generally trend is to use Balance Scorecard Approach for performance measurement of small organizations. Approach focuses on integration of four aspects which are: financial measures, internal process, learning and customers. Henri (2004) was of the view that organization's performance can be measured by using different approaches which include: Goal approach, Time frame approach, Ineffectiveness approach, System approach \& Balance Scorecard Approach. Etzioni (1960) acknowledged that Performance of any organization can be evaluated by focusing on its ability to accomplish its goals i.e. by using Goal Approach.

Yucthman, Seashore (1967) provided details about System Approach which measures the performance on the basis that how much access organization has to its inputs or resources? Daft (1995) pointed that performance can be measured by evaluating the capability of an organization to meet its stake holder's needs \& demands i.e. through Stakeholder Approach. Quinn, Rohrbaugh (1981) stated that Competing Value Approach is based on developing four other models which include: rational goal, open system, internal process \& human relations. This approach expands the series of other approaches.

Pfeffer, Salancik (1978) explained that among Goal approach, System Approach, Balance Scorecard Approach, Ineffectiveness approach; Goal Approach is considered as the best approach for performance measurement due to its straightforwardness. Neely et al (1999) were of the view that Balance Scorecard Approach evaluates the performance of an organization by balancing financial \& non-financial measures. It helps in looking \& moving towards progress. Mochal (2003) pointed out that Matrices can be used as a basis for performance measurement. An effective Benchmarking program is to be implemented which makes organization successful in marketplace. Program requires blend of predefined matrices which results in well-defined processes.

Henezel (2002) explained that to measure performance, organizations establish some standards. Then, they gauge \& evaluate their strategies, values, practices \& performance against Benchmark (high performance organization anywhere in the world.) Antony, Bhattacharyya (2010) provided that organization's performance \& excellence can be measured by proposing a conceptual framework which contains variables. Excellence is redefined as the ability of one performance variable to influence the other performance variable in an organization. Staw , Epstein (2000) gave the idea that small organizations can evaluate their performance by using conventional accounting measures of profit. For example Return on Assets which is obtained as the annual profit or net income divided by the average assets over the year.

Van Dyck et al (2005) stated that Return on Assets can evaluate operational efficiency as well as overall performance of small organizations by reflecting long term financial strength. But it is not always an optimal measure. Huselid (1995) suggested that profit is associated with 
performance but compute output of employees to evaluate organization's performance. Productivity/output is obtained as the revenue divided by total number of employees. Salamon, Robinson (2008) stated that to determine the performance of organization, sales or sometimes variants of sales can be utilized e.g. sales relative to target. In this approach, sales performance of each site is to be calculated to arrive at overall performance of organization. Sales performance of a site will be better if employees of site felt responsibility and accountability.

Gong et al (2009) were of the view that performance can be evaluated by using related measures of sales e.g. total sales growth. Studies show that many HR systems can enhance the performance including Career Planning, Extensive Training, Competitive Pay, and Participation in Decision Making \& Performance Appraisal. Delaney, Huselid (1996) pointed out that to evaluate performance, utilize measures which combine benefits of subjective measures with merits of objective measures. For example series of subjective questions may be asked from contestants to acquire objective measures.

Ostraff (1992) explained that measures specific to particular industries can evaluate the performance. For example, to measure performance of a school, five realms were established: student contentment, student performance, teacher's turnover, academic achievement \& managerial performance. Taticchi, Balachandran (2008) stated that now a day, organizations give much attention to measure their performance by utilizing Performance Measurement \& Management (PMM) Systems but they felt difficulty in implementing these systems. To overcome difficulty, organizations should use framework which integrates five systems: a cost system, planning system, a benchmarking system, a performance system, a capability evaluation system.

McAdam et al (2008) were of the view to develop a theoretical model for performance evaluation and benchmarking. There is a need to develop new approaches to evaluate the performance due to environmental instability, rapid changes in technology \& market. Lockamy (1998) provided that Performance measurement system is very much essential for organizational actions, firm's strategies \& performance. Long term objectives are important for effective performance of organization \& to gain competitive edge in specific markets or market segments. Gomes et al (2004) suggested that both financial and non-financial measures can evaluate the performance but study shows that non-financial measures are more important \& useful for performance measurement of small organizations.

Behn (2003) stated that basic purpose of performance evaluation is to improve performance but measures that are not directly linked with improving performance (like measures that are aimed at better communication with employees to build trust) are measures are meant to achieve that ultimate purpose of performance evaluation.

Kravchuk, Schack (1996) explained that performance is measured for evaluating how well organization is performing? For this purpose management need to know what were strategies, mission, vision set by the organization before it at time of establishment.

\section{Research Design}

This study was conducted on the SMEs located in Lahore, Pakistan. The data was collected through a structured questionnaire and was analysed using SPSS. 


\section{Data Analysis}

The information collected from the respondents is presented here in the form of tables and graphs.

Table 1: Maintaining Record of Revenues

\begin{tabular}{|l|l|l|}
\hline Particular & Frequency & (\%age) \\
\hline Yes & 161 & $80.9 \%$ \\
\hline No & 38 & $19.1 \%$ \\
\hline & 199 & $100 \%$ \\
\hline
\end{tabular}

Table 1 shows that $81 \%$ of the SMEs maintain the record of their revenue whereas the remaining $19 \%$ of the SMEs don't maintain record of their revenue. It may be concluded that SMEs in Pakistan maintain the record of their revenues

Figure 1: Maintaining Record of Revenues

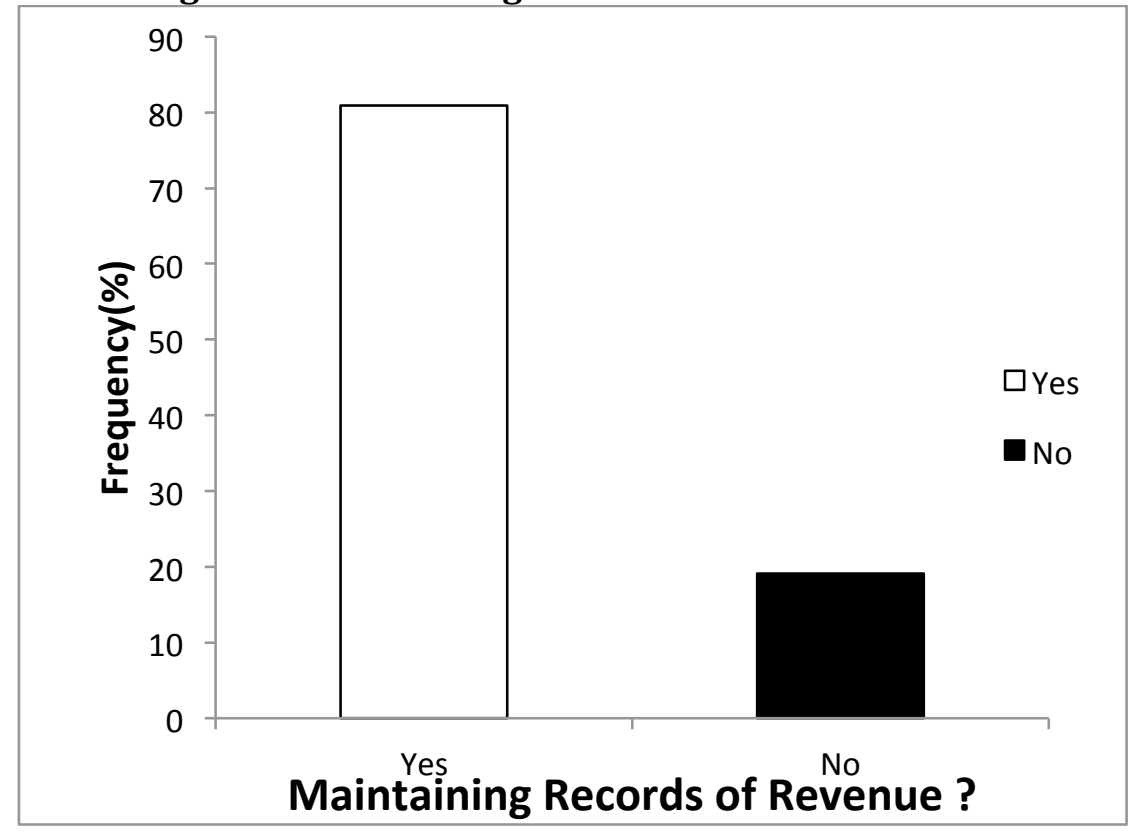

Table 2: Calculating profit on regular basis

\begin{tabular}{|c|c|c|}
\hline Particular & Frequency & (\%age) \\
\hline Yes & 87 & 43.7 \\
\hline No & 112 & 56.3 \\
\hline Total & 199 & 100 \\
\hline
\end{tabular}

Table 2 shows that almost 44\% SMEs calculate their profit on regular basis whereas the remaining 56\% SMEs did not maintain there profit on regular bas is. It may be concluded that more than 50\% SMEs did not maintains their profit on regular basis. 
Figure 2: Calculating profit on regular basis

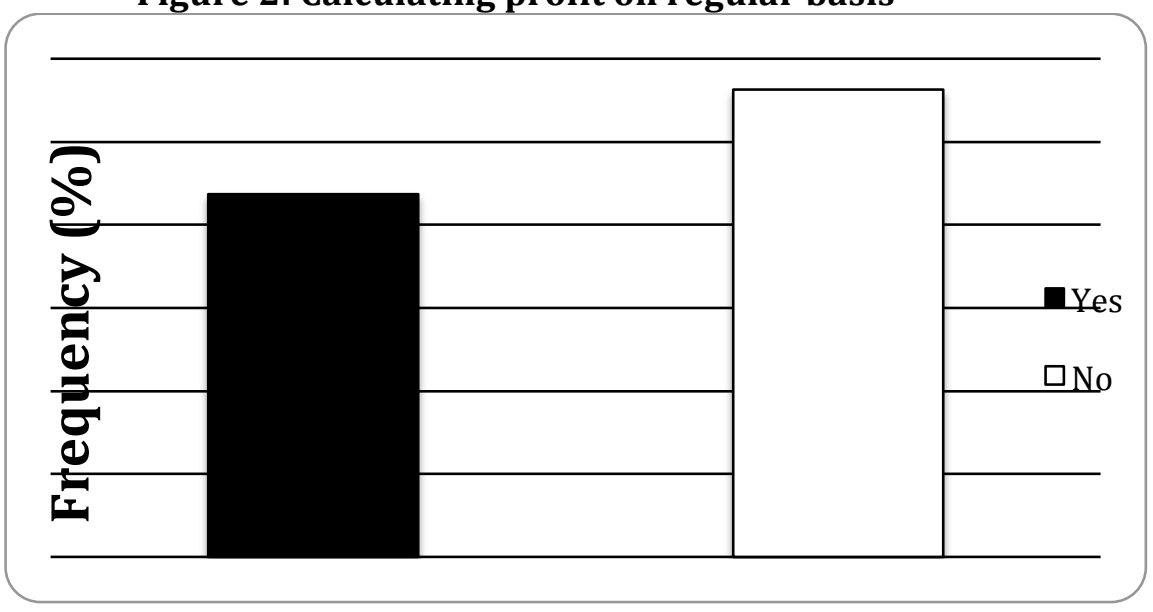

Table 3: Calculating Profit on Regular Basis

\begin{tabular}{|l|l|l|}
\hline \multicolumn{3}{|c|}{ Performance Evaluation Measure } \\
\hline Particular & Frequency & (\%age) \\
\hline Sales Revenue & 50 & 25.1 \\
\hline Profitability & 66 & 33.2 \\
\hline Number of customers & 45 & 22.6 \\
\hline Market Share & 38 & 19.1 \\
\hline & 199 & 100 \\
\hline
\end{tabular}

Table 3 shows that $25 \%$ of SMEs through sales revenue was their performance evaluation measure. 33\% SMEs were of the view that profitability was their performance evaluation measure. 23\% SMEs said that Number of Customers was their performance evaluation measure and almost 19\% SMEs said that Market Share was their performance evaluation measure. Results showed that profitability was the most popular measure of performance evaluation among others.

Table 4: Performance Evaluation Measure in Relation to Competitors

\begin{tabular}{|l|l|l|}
\hline Particular & Frequency & (\%age) \\
\hline Sales Revenue & 58 & $29.1 \%$ \\
\hline Profitability & 45 & $22.6 \%$ \\
\hline No of Customers & 69 & $34.7 \%$ \\
\hline Market Share & 27 & $13.6 \%$ \\
\hline & $\mathbf{1 9 9}$ & $\mathbf{1 0 0 \%}$ \\
\hline
\end{tabular}

Table 4 shows that 29\% SMEs were of the view that sales revenue was their performance evaluation measure when they compared their performance with their competitors. 22\% SMEs said that they used profitability for performance comparison with competitors. 35\% SMEs supported number of customers as criteria for comparison \& 14\% SMEs used market share. No one supported Marketing Techniques for this purpose. Results showed that most of the people used profitability for performance comparison with competitors. 
Table 5: Measures to Judge

\begin{tabular}{|l|l|l|}
\hline Particular & Frequency & (\%age) \\
\hline Personal Judgment & 56 & $28.1 \%$ \\
\hline Comment Card & 56 & $28.1 \%$ \\
\hline Number of old Customers & 47 & $23.6 \%$ \\
\hline Number of visits by a customer during a time period & 70 & $35.2 \%$ \\
\hline & 199 & $100 \%$ \\
\hline
\end{tabular}

Table 5 shows that $28 \%$ SMEs were of the view that they used comment card to judge the level of customer satisfaction. 28\% SMEs also used personal judgment. 24\% SMEs observed number of visits by a customer during a particular time period to judge satisfaction of customers \& $35 \%$ SMEs used number of old customers for this purpose. Results showed that observing number of old customers was the most popular way to judge the level of customer satisfaction.

\section{CONCLUSIONS}

The Research study shows that most of the people maintain record of their revenues to measure performance of their organizations. Profitability is also a determinant of performance when it is compared with competitors but people don't calculate their profit on regular basis to evaluate performance.

Research shows that sales revenue, profitability \& customers are the basic focuses of small businesses to measure their performance. These aspects are included in Balance Scorecard Approach. It is multidimensional approach for performance evaluation. This approach incorporates performance \& exertions from lowest level in the organization to achieve quality, superiority \& distinction in overall performance of organization. Most important aspect of Balance Scorecard Approach is customer satisfaction. If customers are satisfied with products \& services provided by organization, then it can be said that organization is performing well. In fact customers are assets which can maximize your return.

Literature also supports usage of Goal Approach for performance evaluation by small business organizations but this approach focuses only on goals. For such organizations which use goal approach for performance evaluation, goals must be SMART; otherwise inadequate goals may lead the organization to ineffectiveness.

Some small business organizations also use other approaches for performance evaluation like System Approach, Hybrid Approach, Comparative Analysis Approach, Ineffectiveness Approach $\&$ Stakeholder Approach but all these approaches are not very much popular for performance measurement \& are not frequently used.

\section{References}

Antony, J. P., and Bhattacharyya, S. (2010), Measuring organizational performance and organizational excellence of SMEs - Part 1: a conceptual framework. Measuring Business Excellence. 14(2), 3-11.

Behn, R. D. (2003), Why Measure Performance? Different purposes require different measures. Public Administration Review. 63(5), 586-606.

Daft, R. L. (1995). Organization Theory and Design, West Publishing, New York. 
Delaney, J., and Huselid, M. (1996), The impact of human resource management practices on perceptions of organizational performance. Academy of Management Journal. 39, 949-969.

Etzioni, A. (1960), Two approaches to organizational analysis: A critique and a suggestion. Administrative science Quarterly. 5, 257-278.

Garengo, P., Biazzo, S., and Bititci, U. S. (2005), Performance measurement systems in SMEs: A review for a research agenda. International Journal of Management Reviews.7(1), 25-47.

Gomes, C. F., Yasin M. M., and Lisboa, J. V. (2004), An examination of manufacturing organizations' performance evaluation: Analysis, implications and a framework for future research. International Journal of Operations \& Production Management. 24(5), 488-513.

Gong, Y., Law, K. S., Chang, S., and Xin, K. R. (2009), Human resources management and firm performance: The differential role of managerial affective and continuance commitment. Journal of Applied Psychology. 94, 263-275.

Henczel, S. (2002), Benchmarking measuring and comparing for continuous improvement. Information Outlook. $6(7)$.

Henri, J. F. (2004), Performance measurement and organizational effectiveness: bridging the gap. Managerial Finance. 30(6), 93-123.

Huselid, M. A. (1995), The impact of human resource management practices on turnover, productivity, and corporate financial performance. Academy of Management Journal. 38, 635-672.

Kaplan, R. S., and Norton, D. P. (1992), The balanced scorecard - Measures that drive performance. Harvard Business Review. 71-79.

Kravchuk, R. S., and Schack, R. W. (1996), Designing effective performance measurement systems under the Government Performance and Results Act of 1993. Public Administration Review. 56(4), 348-358.

Lockamy, A. (1998) Quality-focused performance measurement systems: a normative model. International Journal of Operations \& Production Management. 18(8), 740-766.

McAdam, R., Hazlett, S. A., and Anderson-Gillespie, K. (2008), Developing a conceptual model of lead performance measurement and benchmarking: A multiple case analysis. International Journal of Operations \& Production Management. 28(12), 1153-1185.

Mochal, T. (2003), Plan your benchmarking approach before starting to collect metrics.

Neely, A. (1999), The performance measurement revolution: why now and what next?. International Journal of Operations \& Production Management. 19(2), 205-23.

Ostroff, C. (1992), The relationship between satisfaction, attitudes, and performance: An organizational level analysis. Journal of Applied Psychology. 77, 963-974.

Pfeffer, J., and Salancik, G. R. (1978). The External Control of Organizations: A Resource Dependence Perspective, Harper and Row, New York.

Quinn, E. R., and Rohrbaugh, J. (1981), A Competing Values Approach to Organizational Effectiveness. Public Productivity Review. 5, 122-140.

Salamon, S. D., and Robinson, S. L. (2008), Trust that binds: The impact of collective felt trust on organizational performance. Journal of Applied Psychology. 93, 593-601.

Staw, B. M., and Epstein, L. D. (2000), What bandwagons bring: Effects of popular management techniques on corporate performance, reputation, and CEO pay. Administrative Science Quarterly. 45, 523-556.

Taticchi, P., and Balachandran, K. R. (2008), Forward performance measurement and management integrated frameworks. International Journal of Accounting and Information Management. 6(2), 140-154.

Van Dyck, C., Frese, M., Baer, M., and Sonnentag, S. (2005), Organizational error management culture and its impact on performance: A two-study replication. Journal of Applied Psychology. 90, 1228-1240.

Yuchtman, E., and Seashore S. (1967), A system resource approach to organizational effectiveness. American Sociological Review. 32, 891-903. 